\title{
Design, Control and Validation of Two-Speed Clutch-less Automatic Transmission for Electric Vehicle
}

\author{
Yonggang Liu, Senior Member, IEEE, Jun Xie, Datong Qin, Yuanjian Zhang, Member, IEEE, Zheng \\ Chen, Senior Member, IEEE, Guang Li, Senior Member, IEEE, and Yi Zhang
}

\begin{abstract}
Two-speed or multiple-speed automatic transmissions can obviously improve the overall manipulating performance in terms of shifting quality and energy efficiency when equipped in electric vehicles (EVs). This study details the design of a two-speed clutch-less automatic transmission (2AT) for EVs and the motor controlled shifting mechanism. Firstly, a novel two-speed clutch automatic transmission is devised with a motor-controlled shifting mechanism, which enables the shift motions and the speed control of the driving motor for synchronization during shifts. Secondly, a coordinated control strategy of the driving motor and controlling motor for shifting is detailed during different shifting processes to achieve fast and smooth shifting. The torque trajectory optimization during synchronizing process is attained by applying the Pontryagin's minimum principle. The simulation and experimental results verify the shifting mechanism design and the shift control algorithm in terms of shift response and smoothness for the designed $2 \mathrm{AT}$.
\end{abstract}

Index Terms-Coordinated control, electric vehicles (EVs), gear shifting control, two-speed automatic transmission (2AT).

\section{INTRODUCTION}

$\mathrm{N}$ OWADAYS, electric vehicles (EVs) have attracted wide attention due to their mitigation of environmental pollution and greenhouse gas emission. Compared to internal combustion engine (ICE) driven vehicles, EVs feature the advantage of faster torque response and higher operating efficiency [1]. The powertrain system of EVs is mainly composed of battery, driving motor, transmission and reducer. Nowadays, most of EVs are equipped with a fixed ratio transmission, since the electric motor is able to operate in a wide speed range [2]. Electric motor features constant torque characteristics, which can provide maximum output from zero to a turning speed and consequent constant power as the speed increases [3]. However, the driving motor cannot operate in the high-efficiency region in both high and low speed range with a fixed gear ratio transmission, thus leading to lower energy transmitting efficiency [4].

To improve the driving performance and powertrain efficiency, the multi-speed transmissions are introduced for EVs [5]. Ref. [6] compares energy consumption of EVs with

This work was founded in part by the National Science Foundation of China (No. U1764259), in part by the National Key R\&D Program of China (2019YFE0121300), in part by Chongqing Fundamental Research and Frontier Exploration Project (No. CSTC2018JCYJAX0409), and in part by the EUfunded Marie Skłodowska-Curie Individual Fellowships Project (No. 845102). (Corresponding Authors: Zheng Chen, and Yonggang Liu)

Y. Liu, J. Xie, and D. Qin are State Key Laboratory of Mechanical Transmissions \& College of Mechanical and Vehicle Engineering, Chongqing University, Chongqing 400044, China. (andylyg@umich.edu, xiejun@cqu.edu.cn,dtqin@cqu.edu.cn) respect to the varied and fixed ratio transmission over a standard driving cycle and highlights that the overall energy efficiency can be improved by 5 to $12 \%$ when equipped with a multi ratio gearbox. Moreover, a multi-speed transmission also provides certain room of downsizing the motor power and reducing powertrain cost [7]. Currently, design and control research of multi-speed transmissions have been widely performed. To improve the operating efficiency and avoid the defect of massive size and weight, a three-speed transmission combining two motors and one clutch is introduced in [8]. Moreover, a four-speed automatic transmission (AT) with dual motors is applied in electric buses, and the shifting scheme is resolved by dynamic programming [9]. In addition, dual clutch transmissions (DCT) for EVs have been widely investigated in [10-12], where the driving motor, clutch, hydraulic clutch actuator and multi-body dynamics of powertrain are modeled. The corresponding power-on and power-off control strategies are designed for both up and down gear shifts.

Nonetheless, the multi-speed transmissions discussed above, to the authors' knowledge, are equipped with clutches or with more than two gears, indicating they include a complicated gear system and require multiple actuators [13]. Due to the high fabricating cost and complicated control strategy, it is difficult to be widely equipped in cost-sensitive EVs [14], such as commercial EVs including electric trucks and electric buses. In this context, two-speed clutch-less automatic transmissions (ATs), which originate from manual transmissions and are equipped with electric shifting mechanism, have been widely investigated and adopted. Unlike the DCT and AT with planetary gear deployed in passenger vehicles, the shifting process of the two-speed clutch-less AT needs to be power-off; however, this type of transmission has great advantages of low cost, simple structure and high transmission efficiency [15]. In [16], the performance comparison of EVs when equipped with different transmissions is discussed, and the results reveal that the two-speed AT can lead to a preferable energy consumption economy. Ref. [17] verifies that by employing proper control

Yuanjian Zhang is with the School of Mechanical and Aerospace Engineering, Queen's University of Belfast, BT9 5AG, Northern Ireland. (y.zhang@qub.ac.uk).

Z. Chen is with the Faculty of Transportation Engineering, Kunming University of Science and Technology, Kunming, 650500, China, and with the School of Engineering and Materials Science, Queen Mary University of London, London, E1 4NS, United Kingdom. (chen@kust.edu.cn).

G. Li is with the School of Engineering and Materials Science, Queen Mary University of London, London, E1 4NS, United Kingdom. (g.li@qmul.ac.uk).

Yi Zhang is with the Department of Mechanical Engineering, University of Michigan-Dearborn, Dearborn, MI 48128, USA. (anding@umich.edu) 
strategies for the shifting mechanism and the driving motor, the gear shifting performance of clutch-less AT outperforms that of the traditional ones for EV applications. In summary, by deploying a two-speed clutch-less AT to EV, particularly commercial EVs, the size, weight and cost of the driving motor can be reduced, and the efficiency of EVs can be improved, only with the slight, or even neglectable, price of cost increase.

Different from EVs with fixed ratio transmission, EV with AT entails fast and smooth shifting operations [18]. Currently, studies in terms of shift of AT can be divided into two main categories: design of shift mechanism and optimization of control method. To reveal the influences of driving motor and shift mechanism on the gear shifting performance of AT, a multi-body dynamics model is introduced in [19] to depict the transient behavior of the AT system during gear shifting. In [20], a novel dual-wedge shift actuator is introduced for attaining the self-reinforcement by choosing proper working slopes. By this manner, the self-weakening effect is avoided, and consequently the shifting duration is shortened.

Actually, proper control of driving motor and shift mechanism can facilitate fast and smooth response of shifting [21]. For revealing the requirements of proper shifting control for a clutch-less transmission in EVs, Ref. [22] indicates that the driving motor with the capability of rapid mode-switching and shift mechanism with the robust position control are indispensable in shift operation. In [23], the calculus of variation is applied to determine the optimal angular-velocity schedule of driving motor during gear shifting, thereby leading to the optimal trajectory of transmission angular velocities. In [24], a hybrid automation model is put forward to optimize the shift force and relative rotational speed of different gears in gear engagement process for attaining smooth shifting. In short, the current shift control optimization focuses on optimizing the speed of the driving motor and the force of shift control motor.

Obviously, the significant influence of driving motor control and the shift force control on shifting performance for EV has been a consensus. However, the structural design of the shift mechanism and shift force trajectory planning still need to be further investigated through analyzing the dynamic performance during the shifting process. Moreover, seldom research is focused on the coordinated control between the driving motor and shift mechanism, which can play a critical role in promoting the shifting performance. Motivated by this, this study designs a novel two-speed clutch-less automatic transmission (2AT) for EVs, and it only needs to control a single motor to rotate the camshaft unidirectionally through the worm gear mechanism, so as to facilitate fast and smooth shifting operation. Furthermore, the shifting process is optimized by conducting the coordinated control on the driving motor and shift mechanism. To this end, firstly, the camshaft, as a key component of the shift mechanism, is elaborately designed according to the detailed shift force analysis, and the parameters of the control motor of camshaft and the gear ratio of worm gear are optimized. Then, the coordinated control strategies of the driving and control motors are designed with the target of fast and smooth shifting by dividing the shifting process into three stages, i.e., before-gear-disengagement, gear- disengagement and gear-engagement. For the gear-engagement stage, the working process of the synchronizer is investigated, and the torque trajectory of the shift control motor for synchronization is optimized by applying the Pontryagin's minimum principle (PMP). Finally, the simulation and experiment validation verify the feasibility of the novel $2 \mathrm{AT}$ mechanism and the consequent control strategy.

The remainder of this paper is arranged as follows. Section II elaborates the detailed design of the proposed novel shift mechanism, which is mainly comprised of a camshaft, a control motor and a worm gear. Next, the shifting process of the designed 2AT is analyzed, and the control strategy of both the driving and control motors during different shifting processes is illustrated in Section III. In addition, the synchronizing trajectory of torques of control motor is optimized by the PMP. Section IV presents the simulation of the upshift and downshifting processes with the integrated vehicle control model, followed by an experimental validation. Finally, the conclusions and future work are drawn in Section V.

\section{Design of Two-SPEEd Non-Clutch Automatic TRANSMISSION}

As well known, manual transmissions feature simple structure, high efficiency, easy fabrication and low cost [25]. By incorporating advantages of manual transmissions, a $2 \mathrm{AT}$ is developed for EVs, of which the mechanical structure is depicted in Fig. 1. The power output of the driving motor is transmitted to the driving shaft through the designed 2AT. The transmission adopts a clutch-less design, which is equipped with an electric shift mechanism. Table I lists the main parameters of EV in this paper.

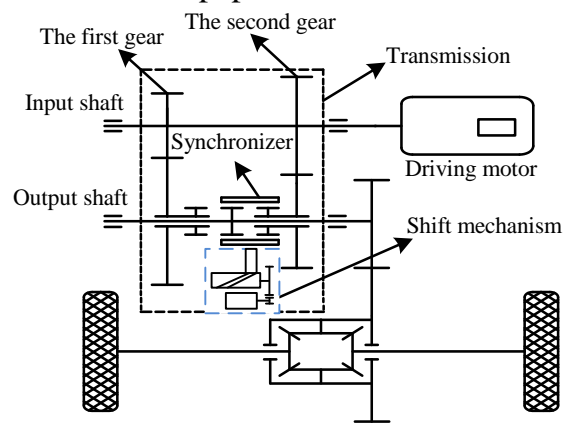

Fig. 1. Structure of the two-speed clutch less automatic transmission. TABLE I

\begin{tabular}{ll}
\multicolumn{2}{c}{ MAIN PARAMETERS OF EV } \\
\hline \hline Parameters & Value \\
\hline Air drag coefficient & 0.8 \\
Frontal projected area & $3.76 \mathrm{~m}^{2}$ \\
Roll resistance coefficient & 0.0235 \\
Mass & $3650 \mathrm{~kg}$ \\
Rolling radius & $0.375 \mathrm{~m}$ \\
Final drive ratio & 5.375 \\
Gear ratio & $2.54 / 1.00$ \\
\hline \hline
\end{tabular}

The main components of shifting mechanism, shown in Fig. 2 , include a worm gear reducer, a synchronizer, a shifting fork, a control motor and a cylindrical cam that connects the control motor and the shifting fork.

Among them, the key component is the cylindrical cam, which converts the rotational motion of the control motor into linear motion of the shifting fork to engage or disengage a gear. 
Compared with conventional designs, where gear selecting and gear engaging are respectively controlled by a motor, the devised topology is simpler and more space-saving. Moreover, the worm gear reducer enables one-way lock, which will not transmit power in reverse direction during shifting. The synchronizer in this study is a single cone ring-type inertia synchronizer, of which the structure is shown in Fig. 3.

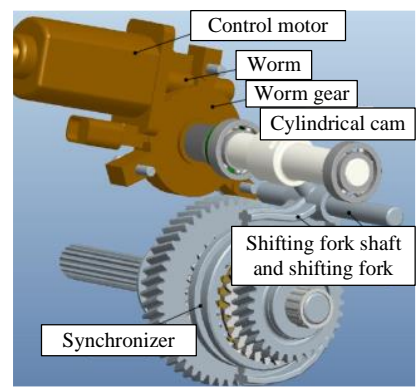

Fig. 2. Structure of the shift mechanism.

Positioning pin Sliding sleeve

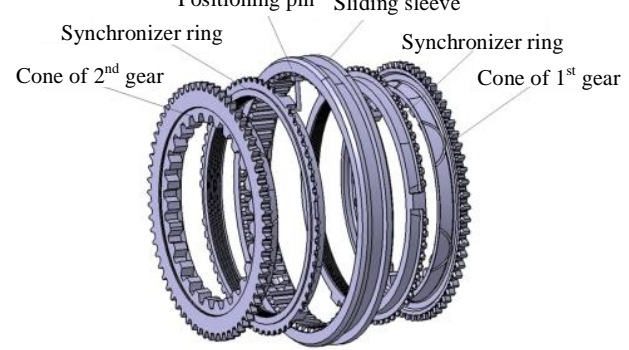

Fig. 3. Structure of the synchronizer.

\section{A. Shift Force Analysis}

In the gear-engagement process, the shift force provided by control motor needs to overcome the maximum synchronization resistance, including the self-locking resistance of the sleeve, axial friction, synchronizing resistance and inertial resistance during gear-disengagement [26]. To eliminate the influence of unnecessary nonlinear factors and simplify model construction [27], some assumptions are made in this study, as follows:

1) The vehicle is supposed to drive in a straight and flat road without wind, and the shifting is normally finished within $1 \mathrm{~s}$. Hence, the road condition and vehicle speed are supposed to remain the same before and after shifting.

2) The resistance coefficient of the friction cone and synchronizing resistance are considered as constant.

3) The stiffness of the transmission is ignored.

Based on these assumptions, a simplified dynamic model for the synchronizer when upshifting from $1^{\text {st }}$ to $2^{\text {nd }}$ gear is established by adopting the method in [15], as shown in Fig. 4.

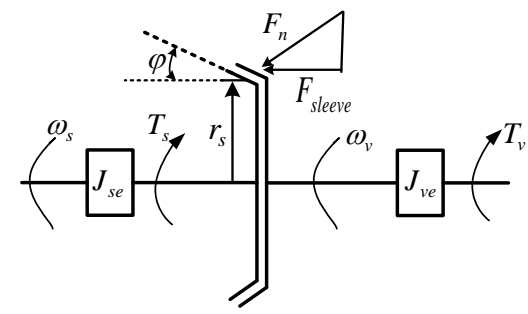

Fig. 4. Synchronizer dynamic model.

The synchronizer driving part is connected to the transmission input shaft including the driving motor, the transmission input shaft, the $1^{\text {st }}$ driving and driven gear, and the $2^{\text {nd }}$ driving and driven gear; and the synchronizer driven part is connected to the gearbox shaft and to the differential, half axles and wheels. The frictional torque can be calculated, as:

$$
T_{s}=\mu_{0} r_{s} F_{\text {sleeve }} / \sin \varphi
$$

where $T_{s}$ denotes the friction torque during synchronization, $F_{\text {sleeve }}$ is the shift force applied to synchronizer ring, $\mu_{0}$ is the friction coefficient of the friction cone, $r_{s}$ denotes the friction radius of the synchronizer ring, and $\varphi$ is the inclination angle of the cone of synchronizer ring. The force of the synchronizer can be calculated, as:

$$
\left\{\begin{array}{l}
J_{s e} \dot{\omega}_{s}=-T_{s} \\
J_{v e} \dot{\omega}_{v}=T_{s}-T_{v}
\end{array}\right.
$$

where $J_{\text {se }}$ denotes the equivalent rotating inertia of the synchronizer driving part, $J_{v e}$ is the equivalent rotating inertia of the synchronizer driven part, $\omega_{s}$ is the angular velocity of the synchronizer driving part, $\omega_{v}$ is the angular velocity of the synchronizer driven part, and $T_{v}$ denotes the resistance torque at the synchronizer driven part. The friction torque of the synchronizer gradually eliminates the speed difference between the driving and driven part of the synchronizer. Thus,

$$
T_{s}=J_{e 1-2} \cdot \Delta \omega_{2} / \Delta t
$$

where $J_{e 1-2}$ represents the equivalent rotating inertia of the synchronizer driving part on the $2^{\text {nd }}$ driving gear, $\Delta t$ is the synchronization time, and $\Delta \omega_{2}$ equals:

$$
\Delta \omega_{2}=\pi \Delta n / 30
$$

where $\Delta n$ is the speed difference between the driving and driven part of the synchronizer. By combining (1), (3) and (4), the shift force for upshifting from the $1^{\text {st }}$ to $2^{\text {nd }}$ gear can be calculated, as:

$$
F_{s 1-2}=\frac{J_{e 1-2} \pi \Delta n \sin \varphi}{30 \mu_{0} r_{s} t_{s}}
$$

where $t_{s}=\Delta t$ denotes the synchronization time. Similarly, the shift force for downshifting from the $2^{\text {nd }}$ to $1^{\text {st }}$ gear can be obtained, as:

$$
F_{s 2-1}=\frac{J_{e 2-1} \pi \Delta n \sin \varphi}{30 \mu_{0} r_{s} t_{s}}
$$

where $J_{e 2-1}$ denotes the equivalent rotating inertia of synchronizer driving part on the $1^{\text {st }}$ driven gear.

\section{B. Design of the Shift Mechanism}

By assuming the synchronization time is $0.2 \mathrm{~s}$, the maximum shift force can be calculated, as listed in Table I. According to the analysis of the shifting process of 2AT, the requirement of the shift mechanism to accomplish the shifting process includes that the shifting displacement is $18 \mathrm{~mm}$, and the shift force should be not less 250 N. Fig. 5 describes the force analysis on the shifting fork pin in the expanded view of cylindrical cam. TABLE II

MAXIMUM SHIFT FORCES

\begin{tabular}{lll}
\hline \hline Gear & Rotating inertia $\left(\mathrm{kg} \cdot \mathrm{m}^{2}\right)$ & Shift force $(\mathrm{N})$ \\
\hline $1^{\text {st }}$ to $2^{\text {nd }}$ & 0.0598 & 87.6 \\
$2^{\text {nd }}$ to $1^{\text {st }}$ & 0.1403 & 205.5 \\
\hline \hline
\end{tabular}




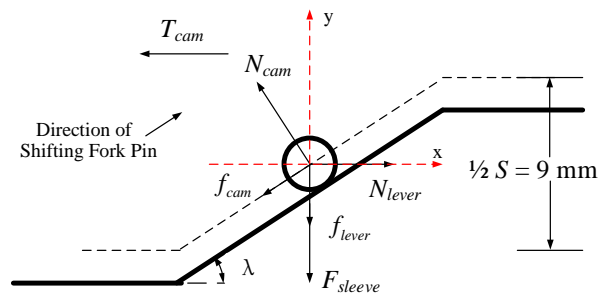

Fig. 5. Force analysis on the shifting fork pin. $T_{\text {cam }}$ is the camshaft torque, $N_{\text {cam }}$ is the resistance from the camshaft groove, $f_{\text {cam }}$ is the friction resistance from the camshaft groove, $N_{\text {lever }}$ is the pressure of the shifting fork on the shifting fork shaft, $f_{\text {lever }}$ is the friction resistance as the shifting fork moving, $\lambda$ is the helical angle of the cylindrical cam, and $S$ is the required displacement of the shifting fork pin.

The forces on the shifting fork pin can be formulated, as:

$$
\frac{T_{c a m}}{r_{\text {cam }}}-N_{\text {cam }} \sin \lambda+f_{\text {cam }} \cos \lambda=J_{\text {cam }} \dot{\omega}_{\text {cam }}
$$

where $r_{c a m}$ is the camshaft radius, $J_{\text {cam }}$ is the equivalent rotating inertia on the camshaft, $\dot{\omega}_{\text {cam }}$ is the angular acceleration of the camshaft, and

$$
f_{\text {cam }}=\mu_{\text {cam }} N_{\text {cam }}
$$

where $\mu_{c a m}$ is the friction coefficient of the camshaft groove. Since the shifting fork shaft is fixed on the transmission case and cannot move along the horizontal axis, the force on the $x$ axis can be balanced, and we can get:

$$
N_{\text {lever }}-N_{\text {cam }} \sin \lambda-f_{\text {cam }} \cos \lambda=0
$$

The shifting fork moves on the vertical axis to achieve the shift, and we can get:

$$
N_{\text {cam }} \cos \lambda-f_{\text {cam }} \sin \lambda-F_{\text {sleeve }}-f_{\text {lever }}=m_{\text {sleeve }} a
$$

where $m_{\text {sleeve }}$ is the total mass of sleeve and the shifting fork. The friction resistance as the shifting fork moving $f_{\text {lever }}$ and the axial acceleration of the sleeve $a$ can be calculated as:

$$
\begin{gathered}
a=\dot{\omega}_{\text {cam cam }} r_{\text {can }} \lambda \\
f_{\text {lever }}=\mu_{\text {lever }} N_{\text {lever }}
\end{gathered}
$$

where $\mu_{\text {lever }}$ is the friction coefficient of shifting fork shaft. By combining (7) to (12), the relationship between $F_{\text {sleeve }}$ and $T_{\text {cam }}$ can be yielded, as:

$$
T_{\text {cam }} \geq \frac{F_{\text {sleeve }} r_{\text {cam }}\left(\sin \lambda+\mu_{\text {cam }} \cos \lambda\right)}{\left(1-\mu_{\text {cam }} \mu_{\text {lever }}\right) \cos \lambda-\left(\mu_{\text {cam }}+\mu_{\text {lever }}\right) \sin \lambda}
$$

Then, the constraint of control motor can be formulated, as:

$$
T_{s m} \geq \frac{F_{\text {sleeve }} r_{\text {cam }}\left(\sin \lambda+\mu_{\text {cam }} \cos \lambda\right)}{i_{w} \eta_{w}\left[\left(1-\mu_{\text {cam }} \mu_{\text {lever }}\right) \cos \lambda-\left(\mu_{\text {cam }}+\mu_{\text {lever }}\right) \sin \lambda\right]}
$$

where $T_{s m}$ is the torque of the control motor, $i_{w}$ denotes the gear ratio of worm gear, and $\eta_{w}$ is the worm gear efficiency. Here we assume that the time required for gear-engagement is $0.4 \mathrm{~s}$, thus the relationship between the speed of the control motor and the angle of the shifting cam can be calculated, as:

$$
n_{s m}=60 \Gamma_{c a m} i_{w} /\left(2 \pi t_{c a m}\right)
$$

where $n_{s m}$ is the speed of the control motor, and $\Gamma_{c a m}$ is the rotation angle of the camshaft, as:

$$
\Gamma_{\text {cam }}=S /\left(r_{\text {cam }} \tan \lambda\right)
$$

The power of the control motor $P_{s m}$ can be calculated as:

$$
P_{s m}=\frac{T_{s m} n_{s m}}{9550}
$$

By combining (13) to (17), the power requirement of the control motor can then be attained:

$$
P_{s m} \geq \frac{0.001 S F_{\text {sleeve }}\left(\tan \lambda+\mu_{\text {cam }}\right) /\left(\eta_{w} T_{\text {cam }}\right)}{\tan \lambda\left[1-\mu_{\text {cam }} \mu_{\text {lever }}-\left(\mu_{\text {cam }}+\mu_{\text {lever }}\right) \tan \lambda\right]}
$$

From (18), except $F_{\text {sleve }}$ and $\lambda$, all the remaining parameters are available now. Table II shows that $F_{\text {sleeve }} \geq 250 \mathrm{~N}$. If $F_{\text {sleeve }}$ equals the minimum value, i.e., $250 \mathrm{~N}$, the relationship between the control motor power and the helix angle of cylindrical cam can be calculated and presented in Fig. 6. As can be seen, when the helix angle of camshaft is $32.23^{\circ}$, the power of control motor is minimum and equals $P_{s m}=0.031 \mathrm{~kW}$. Moreover, the selected power of control motor is generally greater than the minimum value. In this study, we choose a brushless DC motor as the control motor, of which the parameters are shown in Table III.

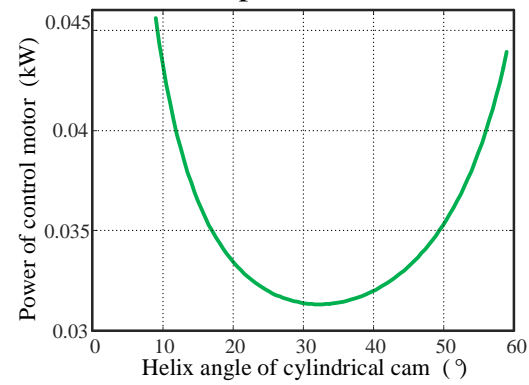

Fig. 6. Relationship between the power of control motor and the helix angle of cylindrical cam.

In this paper, the helix angle of camshaft in the synchronizing process is designed to be $32.5^{\circ}$, as illustrated in Fig. 7. By considering the structure and assembly of transmission, the radius of shifting cam is set to $0.018 \mathrm{~m}$. Based on (16), the rotation angle of the camshaft is $45^{\circ}$ during the gear disengagement. However, the camshaft rotation angle should have a margin to ensure that the shifting fork pin fits in the groove when accomplishing gear disengagement/engagement; therefore, the rotation angle of the camshaft is set to $50^{\circ}$. Considering the requirements of shifting process and operating characteristics of driving and control motors, the rotation angle of each process of the camshaft is shown in Table IV.

TABLE III

PARAMETERS OF THE CONTROL MOTOR

\begin{tabular}{ll}
\hline \hline Parameters & Value \\
\hline Power rating $(\mathrm{kW})$ & 0.05 \\
Peak power $(\mathrm{kW})$ & 0.1 \\
Rated speed $(\mathrm{rpm})$ & 2000 \\
Rated torque $(\mathrm{N})$ & 0.239 \\
Peak torque $(\mathrm{N})$ & 0.4775 \\
\hline \hline
\end{tabular}

As for the gear ratio of worm gear, we can get:

$$
i_{w} \geq \frac{F_{\text {sleeve }} r_{\text {cam }}\left(\sin \lambda+\mu_{\text {cam }} \cos \lambda\right)}{T_{s m} \eta_{w}\left[\left(1-\mu_{\text {cam }} \mu_{\text {lever }}\right) \cos \lambda-\left(\mu_{\text {cam }}+\mu_{\text {lever }}\right) \sin \lambda\right]}
$$

when $F_{\text {sleeve }}$ equals to $250 \mathrm{~N}$. Now, the minimum value of the worm gear ratio can be calculated, as:

$$
i_{w} \geq 31.1
$$

Assuming that the control motor accomplishes the shifting process at the rated speed, the total time of the gear 
disengagement and engagement can be determined, as:

$$
\frac{\Gamma_{\text {cam }}}{\omega_{\text {cam }}}=\frac{60 i_{w} s}{2 \pi n_{\text {ecam }} r_{\text {cam }} \tan \lambda} \leq 0.4
$$

where $n_{\text {ecam }}$ is the rated speed of the control motor. Based on (19), the maximum value of worm gear ratio is calculated, as:

$$
i_{w} \leq \frac{0.8 \pi n_{\text {ecam }} r_{\text {cam }} \tan \lambda}{60 s}
$$

To sum up, the range of the worm gear ratio is $31.1 \leq i_{w} \leq 52.8$, and considering the power of the matched control motor is redundancy, the worm gearing ratio can be taken as a lower value, i.e., $i_{w}=32$.

TABLE IV

CAMSHAFT ANGLE AT EACH SHIFTING PROCESS

\begin{tabular}{ll}
\hline \hline Parameters & Value \\
\hline Torque-releasing process & $48^{\circ}$ \\
Gear-disengagement process & $50^{\circ}$ \\
Speed-adjusting process & $90^{\circ}$ \\
Gear-engagement process & $50^{\circ}$ \\
Torque restoring process & $48^{\circ}$ \\
\hline \hline
\end{tabular}

In the next step, the shifting control strategy will be designed, and the corresponding analysis will be conducted.

\section{ShifTING Control StRATEgy OF THE 2AT}

In this section, a shift control strategy is designed, including the control of driving motor and shift control motor during different shifting processes.

\section{A. Shifting Process}

The in-plane movement of the shifting groove is divided into five sections, as shown in Fig. 7. As can be seen, when the shifting fork pin moves into the first part, the transmission is engaged in the $1^{\text {st }}$ gear. Similarly, the fifth part is for the $2^{\text {nd }}$ gear. The second and fourth parts represent the process of gearengagement or disengagement. The neutral position of the transmission is the third part.

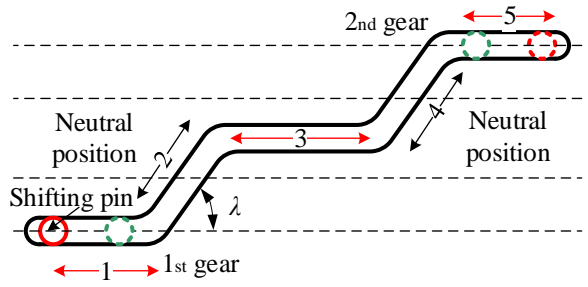

Fig. 7. The expanded view of shifting groove.

When the shifting fork pin locates in the first, third, or fifth part of the shifting groove, the rotational motion of camshaft does not generate the axial movement of the sleeve. Thus, the driving motor and control motor can work simultaneously to reduce the shifting time in these three parts through the parallel coordinated control.

The shifting process can be divided into five steps: torque release, gear disengagement, speed adjustment, gear engagement and torque restoration. In the torque release process, the control motor is idle and waits for the torque clearance of the driving motor, and next in the gear disengagement process, the control motor drives the camshaft to move the shifting fork pin to the neutral zone. Then, as the shifting fork pin locates at the beginning of the neutral zone, the speed of driving motor begins to be regulated to the target speed of the next gear; and meanwhile, the control motor drives the camshaft to cross the neutral zone. Finally, the gear engagement and torque restoration are conducted; and after the control motor turns the synchronizer to engage into the target gear, and the torque of driving motor is restored. Note that in this study, the upshifting process is taken as the example. The downshift control process is similar to the upshift detailed in this paper.

In the gear engagement/disengagement process, the driving motor operates in the free mode. The control strategy of the driving motor in other processes is detailed as follow.

\section{1) Control Strategy for Torque-Release/Restoration}

The impact on shift smoothness during the processes of torque release and restoration is caused by the output torque variation of vehicle powertrain. To mitigate it, the torque changing rate of the driving motor should satisfy:

$$
\frac{d T_{m}}{d t} \leq \frac{j_{1} \delta m r}{i_{g n} i_{0}}
$$

where $T_{m}$ is the torque of driving motor, $\delta$ is the rotating mass coefficient, $i_{g n}$ is the gear ratio, $i_{0}$ is the gear ratio of final drive, $m$ is the vehicle mass, $r$ is the wheel radius, and $j_{1}$ is the variation rate of torque on wheel, also known as shift impact, which should be smaller than $10 \mathrm{~m} / \mathrm{s}^{3}$ according to the engineering experience.

\section{2) Control Strategy for Speed-adjusting Process}

In this process, the driving motor operates in the speed mode, and the driving motor speed is controlled to follow the target speed, which can be calculated, as:

$$
n_{\text {targat }}=n_{0} i_{g n}+\Delta N
$$

where $n_{\text {targat }}$ is the target speed of the driving motor, $n_{0}$ is the speed of the transmission output shaft, and $\Delta N$ is the adjustment value of the target speed, which is taken as $50 \mathrm{r} / \mathrm{m}$ in each control period.

\section{B. Control Strategy of the Control Motor}

According to the position of the synchronizer, the control strategy of the control motor is detailed in two shifting processes: the gear-disengagement and gear-engagement.

1) Control Strategy for Gear-Disengagement Process

Once the torque of the driving motor is zero, the control motor drives the shifting fork pin to move from the $1^{\text {st }}$ gear zone to the neutral zone. When the driving motor conducts the speed adjustment, the control motor will drive the shifting fork pin to the end of neutral zone. The axial movement of sleeve in this process should be subjected to the inertial resistance, as:

$$
F_{\text {inertia }}=J_{e 2-1}\left|\dot{\omega}_{v}\right| / r_{s y n}
$$

where $F_{\text {inertia }}$ is the inertial resistance during the geardisengagement process, $\omega_{v}$ is the angular velocity of synchronizer driven part, and $r_{s y n}$ is the reference radius of the synchronizer ring. The dynamic equation of the camshaft can be obtained by (7), (9) and (25), as:

$$
J_{\text {cam }}^{e} \ddot{\Gamma}_{\text {cam }}=T_{s m} i_{w} \eta_{w}-\frac{J_{e 2-1} r_{\text {cam }} \mu_{\text {ring }}\left|\dot{\omega}_{v}\right|\left(\tan \lambda+\mu_{\text {cam }}\right)}{r_{\text {syn }}\left[1-\mu_{\text {cam }} \mu_{\text {lever }}-\left(\mu_{\text {cam }}+\mu_{\text {lever }}\right) \tan \lambda\right]}
$$

where $\mu_{\text {ring }}$ is the friction coefficient between the sleeve and the synchronizer ring, $\ddot{\Gamma}_{c a m}$ is the angular acceleration of the 
camshaft rotation angle, and the equivalent rotating inertia of the camshaft $J_{\text {cam }}^{e}$ can be calculated, as:

$$
J_{\text {cam }}^{e}=J_{\text {cam }}+\frac{m_{\text {sleve }} r_{\text {cam }}^{2} \tan \lambda\left(\tan \lambda+\mu_{\text {cam }}\right)}{1-\mu_{\text {cam }} \mu_{\text {lever }}-\left(\mu_{\text {cam }}+\mu_{\text {lever }}\right) \tan \lambda}
$$

since the torque of the driving motor has been reduced to $0 \mathrm{Nm}$, $\left|\dot{\omega}_{v}\right|$ is a determined value. Thus, the resistance torque to camshaft $T_{f}$ can be calculated, as:

$$
T_{f}=\frac{J_{e 2-1} r_{\text {cam }} \mu_{\text {ring }}\left|\dot{\omega}_{v}\right|\left(\tan \lambda+\mu_{\text {cam }}\right)}{r_{\text {syn }}\left[1-\mu_{\text {cam }} \mu_{\text {lever }}-\left(\mu_{\text {cam }}+\mu_{\text {lever }}\right) \tan \lambda\right]}
$$

then, eq. (26) can be expressed as:

$$
T_{s m} i_{w} \eta_{w}-T_{f}=J_{c a m}^{e} \ddot{\Gamma}_{c a m}
$$

Eq. (28) can be used to establish the optimum control model for the gear-disengagement process. The rotation angle of the camshaft $\Gamma_{\text {cam }}$ and its changing rate $\dot{\Gamma}_{\text {cam }}$ are set as state vectors, as shown in (30), the output torque of the control motor is set as the control vector, as shown in (31), and the boundary condition is set in (32).

$$
\begin{aligned}
& X=\left(\begin{array}{l}
x_{1} \\
x_{2}
\end{array}\right)=\left(\begin{array}{l}
\Gamma_{c a m} \\
\dot{\Gamma}_{c a m}
\end{array}\right), \dot{X}=\left(\begin{array}{l}
\dot{x}_{1} \\
\dot{x}_{2}
\end{array}\right)=\left(\begin{array}{c}
x_{2} \\
\frac{T_{s m} i_{w} \eta_{w}-T_{f}}{J_{c a m}^{e}}
\end{array}\right) \\
& u=T_{s m} \\
& x_{1}\left(t_{f}\right)=\Gamma_{2}
\end{aligned}
$$

where $t_{f}$ and $\Gamma_{2}$ denote the end time and the angular displacement during the gear-disengagement process. In addition, an admissible condition of $T_{s m}$ is defined by:

$$
-T_{\text {sm_max }} \leq T_{s m} \leq T_{\text {sm_max }}
$$

where $T_{s m_{\text {max }}}$ denotes the maximum output torque of the control motor. The optimal time of gear-disengagement is taken as the performance function to ensure the gear-disengagement process to be finished as quickly as possible, as:

$$
J=\min \int_{0}^{t_{f}} 1 d t
$$

The optimal control trajectory for the torque of control motor during the gear-disengagement process can be formulated as:

$$
T_{s m}(t)=T_{s m_{-} \max }
$$

2) Control Strategy for Gear-engagement Process

Before applying the control strategy of control motor during the gear-engagement process, the synchronizing process is analyzed in detail.

(a) Analysis of the Working Process of Synchronizer

According to the relative position among the sleeve, synchronizer ring and gear ring, the synchronizer working process is divided into four phases: before-synchronizerlocking phase, synchronizer-locking phase, after-synchronizerlocking phase and engaging-target-gear phase [28]. Fig. 8 shows the synchronizing process of the $1^{\text {st }}$ to $2^{\text {nd }}$ upshift.

Phase 1: Before-Synchronizer-Locking Phase.

As shown in Fig. 8 (a), the sleeve drives the slider to move towards the gear ring to eliminate the gap between the synchronizer ring and the gear ring. By respectively assuming that the rotational speed of the sleeve, the synchronizer ring and the gear ring are $n_{1}, n_{2}$, and $n_{3}$, we can get $n_{3}>n_{2}=n_{1}$.

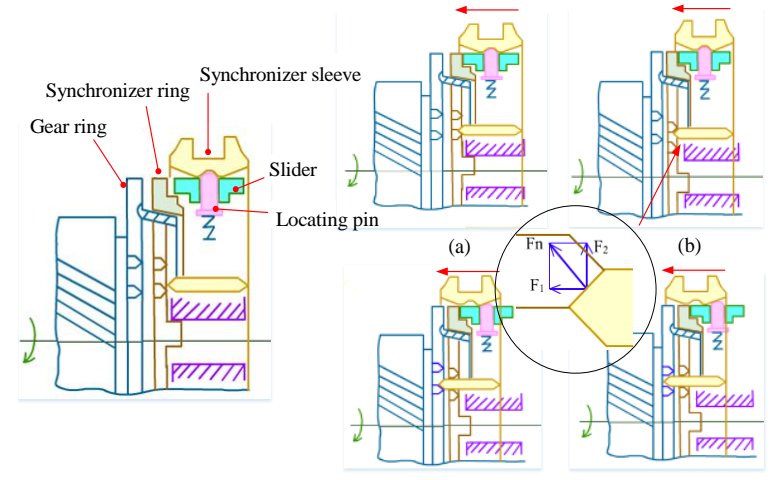

(c)

(d)

Fig. 8. Synchronizing process of the synchronizer.

Phase 2: Synchronizer-Locking Phase.

As shown in Fig. 8 (b), the sleeve cannot move any further because of the conflict with the ring. The synchronizer is locked, and a force $F_{N}$ is generated on the synchronizer ring and is decomposed into an axial force $F_{1}$ and a tangential force $F_{2}$, which respectively generate a friction torque $T_{s}$, trying to reduce the speed difference between the driving and driven parts of the synchronizer ring, and a torque $T_{c}$ attempting to reverse the rotation of the synchronizer ring.

Phase 3: After-Synchronizer-Locking Phase.

As shown in Fig. 8 (c), when $n_{2}$ is equal to $n_{3}$, there is not any speed difference between the synchronizer ring and the gear ring, and thus the friction torque $T_{s}$ disappears. At this moment, $T_{c}$ will drive the ring to rotate to the half tooth of the spline teeth, and the sleeve will continue to move towards the gear ring under the shift force; however, the sleeve spline tooth is still not aligned with the gear ring tooth space.

Phase 4: Engaging-Target-Gear Phase.

As shown in Fig. 8 (d), as the sleeve tooth is not aligned with the gear ring tooth space, a torque would be generated to rotate the gear ring. At this moment, the sleeve will continue to move to the left, and then engage completely with the $2^{\text {nd }}$ gear. A control strategy is adopted to improve the synchronizing quality, which is shown in Fig. 9. In the next step, the four phases of the synchronizing are divided into two parts: non-synchronizerlocking phase and synchronizer-locking phase.

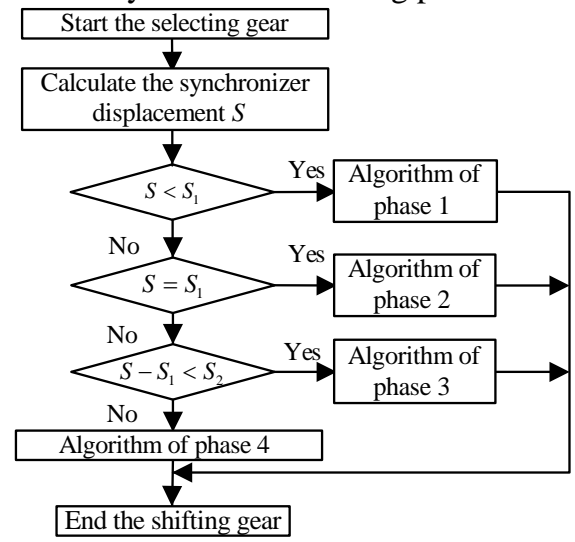

Fig. 9. The control strategy of the synchronizing process. $S$ is the synchronizer displacement, $S_{1}$ denotes the displacement before-synchronizer-locking phase, and $S_{2}$ means the displacement after-synchronizer-locking phase.

(b) Control Strategy for Non-Synchronizer-Locking Phase

The non-synchronizer-locking phase includes phase 1, 3 and 
4. The phase 1 is considered as an example to detail the control strategy, whose target is to regulate the torque to move the sleeve quickly for shortening the phase time. However, to avoid the tooth collision between the sleeve and synchronizer ring before the synchronizer locking, it is imperative to guarantee that the time $t_{1}$ for the synchronizer ring to rotate one tooth width should not be longer than the time $t_{2}$ for the sleeve to move a tooth length of the synchronizer ring, as:

$$
t_{1}=\frac{60}{\Delta n z} \leq \frac{\delta}{v_{\text {sleeve }}}=t_{2}
$$

where $\Delta n$ denotes the speed difference between the driving and driven part of the synchronizer, $z$ is the number of teeth on the synchronizer, $\delta$ is the tooth width of the synchronizer ring, and $v_{\text {sleeve }}$ is the sleeve speed. The sleeve speed can be obtained from (37), as:

$$
v_{\text {sleeve }} \leq \delta \Delta n z / 60
$$

In this phase, a proportional-integral (PI) controller is employed. The control algorithms of phases 3 and 4 are similar to that of phase 1 .

\section{(c) Control Strategy for Synchronizer-Locking Phase}

A multi-objective optimization problem among shift impact, sliding-friction work and locking time of synchronizer is built in the synchronizer-locking stage during the gear-engagement process. According to (2), the state vectors and control vectors can be established. The angular velocity $\omega_{s}$ of the synchronizer driving part, the angular velocity $\omega_{v}$ of the synchronizer driven part and its changing rate are employed as the state vector, as:

$$
X=\left(\begin{array}{l}
x_{1} \\
x_{2} \\
x_{3}
\end{array}\right)=\left(\begin{array}{l}
\omega_{s} \\
\omega_{v} \\
\dot{\omega}_{v}
\end{array}\right)
$$

The synchronizing friction torque $T_{s}$ and its variation rate $\dot{T}_{s}$ are considered as the control inputs, as:

$$
U=\left(\begin{array}{l}
u_{1} \\
u_{2}
\end{array}\right)=\left(\begin{array}{c}
T_{s} \\
\dot{T}_{s}
\end{array}\right)
$$

Combining (2), (38) and (39), the state equations are obtained:

$$
\left\{\begin{array}{l}
\dot{x}_{1}=\dot{\omega}_{s}=-\dot{T}_{s} / J_{s e}=-u_{1} / J_{s e} \\
\dot{x}_{2}=\dot{\omega}_{v}=x_{3} \\
\dot{x}_{3}=\ddot{\omega}_{v}=\left(\dot{T}_{s}-\dot{T}_{v}\right) / J_{v e}=\left(u_{2}-\dot{T}_{v}\right) / J_{v e}
\end{array}\right.
$$

Based on the assumptions made previously, the torque variation $\dot{T}_{v}$ for synchronizer driven part is 0 . Thus, we can get:

$$
\dot{X}=f(X, U, t)
$$

On the basis of the parameters of the shift actuator detailed previously, a maximum synchronizing friction torque can be yielded, that is $T_{s \max }=10.11 \mathrm{Nm}$, therefore

$$
0 \leq T_{s} \leq 10.11
$$

The torque variation rate of control motor should meet the same requirement of the shift impact according to the engineering experience, which is from 0 to $10 \mathrm{~m} / \mathrm{s}^{3}$, and the range of the torque changing rate can be:

$$
0 \leq \frac{\dot{T}_{s} r}{J_{v e} i_{0}} \leq 10
$$

And the initial condition can be defined as:

$$
X\left(t_{0}\right)=X_{0}
$$

where $t_{0}$ is the initial time of the synchronizer-locking phase. The terminal constraint is:

$$
G\left[X\left(t_{f}\right), t_{f}\right]=0
$$

where $t_{f}$ is the end time of the synchronizer locking phase, and $G$ denotes a differentiable function. The sliding-friction work and shift impact are taken as the optimal performance function to improve the shifting quality, as:

$$
J=\int_{t_{0}}^{t_{f}}\left[K_{1} T_{s}\left(\omega_{s}-\omega_{v}\right)+K_{2} j^{2}\right] d t
$$

where $J$ is the performance function, $K_{1}$ and $K_{2}$ are the weight coefficients of the sliding-friction work and shift impact, respectively. $J$ can be expressed as:

$$
J=\int_{t_{0}}^{t_{f}}\left[K_{1} u_{1}\left(x_{1}-x_{2}\right)+K_{2}\left(\frac{r}{J_{v e} i_{0}}\right)^{2} u_{2}^{2}\right] d t
$$

The following function is defined as:

$$
L(X, U, t)=K_{1} u_{1}\left(x_{1}-x_{2}\right)+K_{2}\left(\frac{r}{J_{v e} i_{0}}\right)^{2} u_{2}^{2}
$$

It is known that finding the minimum value of (47) is a typical optimal control problem. Consequently, PMP is introduced for solving the optimal value of $L(X, U, t)$ [29]. According to PMP, the Hamiltonian function can be formulated with a costate variable $\lambda$, as:

$$
H(X, U, \lambda, t)=L(X, U, t)+\lambda^{T} f(X, U, t)
$$

Then, we can get:

$$
H=K_{1} u_{1}\left(x_{1}-x_{2}\right)+K_{2}\left(\frac{r}{J_{v e} i_{0}}\right)^{2} u_{2}^{2}+\lambda_{1}\left(-\frac{1}{J_{s e}}\right) u_{1}+\lambda_{2} x_{3}+\frac{\lambda_{3}}{J_{v e}} u_{2}
$$

The necessary conditions of finding the minimum $J$ is to enable $H\left(X, U, \lambda, t_{f}\right)$ to satisfy the following set of equations:

$$
\dot{\lambda}=-\frac{\partial H}{\partial X}=\left\{\begin{array}{l}
\dot{\lambda}_{1}=-\frac{\partial H}{\partial x_{1}}=-K_{1} u_{1} \\
\dot{\lambda}_{2}=-\frac{\partial H}{\partial x_{2}}=K_{1} u_{1} \\
\dot{\lambda}_{3}=-\frac{\partial H}{\partial x_{3}}=-\lambda_{2}
\end{array}\right.
$$

The Hamiltonian function defines the minimum value on the optimal state $X^{*}$ and the optimal control variables $U^{*}$, as:

$$
H\left[X^{*}, \lambda^{*}, U^{*}, t\right]=\min H\left[X^{*}, \lambda^{*}, U, t\right]
$$

The control equation, boundary condition and transversely condition are given as: 


$$
\begin{gathered}
\frac{\partial H}{\partial U}=\left\{\begin{array}{c}
\frac{\partial H}{\partial u_{1}}=K_{1}\left(x_{1}-x_{2}\right)-\frac{\lambda_{1}}{J_{s e}} \\
\frac{\partial H}{\partial u_{2}}=\frac{2 K_{2} r^{2}}{J_{v e}^{2} i_{0}^{2}} u_{2}+\frac{\lambda_{3}}{J_{v e}} \\
H\left(t_{f}\right)=0 \\
\lambda\left(t_{f}\right)=0
\end{array}\right.
\end{gathered}
$$

Then, the optimal trajectories of each control vector and state vector can be obtained as:

$$
\left\{\begin{array}{l}
T_{s}= \begin{cases}T_{s}\left(t_{0}\right) e^{a\left(t-t_{0}\right)} & 0<T_{s}<10.11 \\
10.11 & T_{s} \geq 10.11\end{cases} \\
\dot{T}_{s}=a T_{s}\left(t_{0}\right) e^{a\left(t-t_{0}\right)} \\
\omega_{c}=-\frac{T_{s}\left(t_{0}\right)}{a J_{s e}}\left(e^{a\left(t-t_{0}\right)}-1\right)+\omega_{c}\left(t_{0}\right) \\
\omega_{s}=\frac{T_{s}\left(t_{0}\right)}{a J_{v e}}\left(e^{a\left(t-t_{0}\right)}-1\right)-\frac{T_{v}}{J_{v e}}\left(t-t_{0}\right)+\omega_{s}\left(t_{0}\right) \\
\omega_{s}=\frac{1}{J_{v e}}\left(T_{s}\left(t_{0}\right) e^{a\left(t-t_{0}\right)}-T_{v}\right)
\end{array}\right.
$$

where $a$ is one of the characteristic root of the co-state variable and is defined by:

$$
a=\left(\frac{K_{1} J_{v e} i_{0}^{2}}{2 K_{2} r^{2}}\right)^{1 / 3}
$$

Finally, by combining (1), (14) and (56), the optimal trajectories of the torque and its variation rate can be found, as:

$$
\begin{gathered}
T_{s m}= \begin{cases}T_{s m}\left(t_{0}\right) e^{a\left(t-t_{0}\right)} & 0<T_{s m}<0.4775 \\
0.4775 & T_{s m} \geq 0.4775\end{cases} \\
\dot{T}_{s m}=a T_{s m}\left(t_{0}\right) e^{a\left(t-t_{0}\right)}
\end{gathered}
$$

The optimal trajectory $T_{s m}$ of the control motor and its variation rate $\dot{T}_{s m}$ are related to $a$ and $\left(K_{1} / K_{2}\right)^{1 / 3}$, of which the latter $\left(K_{1} / K_{2}\right)^{1 / 3}$ can determine the shifting quality to some extent. By assuming that $T_{s m}\left(t_{0}\right)=0.0239 \mathrm{Nm}$, the relationship between the shifting time, the shift impact and the slidingfriction work with $\left(K_{1} / K_{2}\right)^{1 / 3}$ is gained through simulation, as shown in Fig. 10.

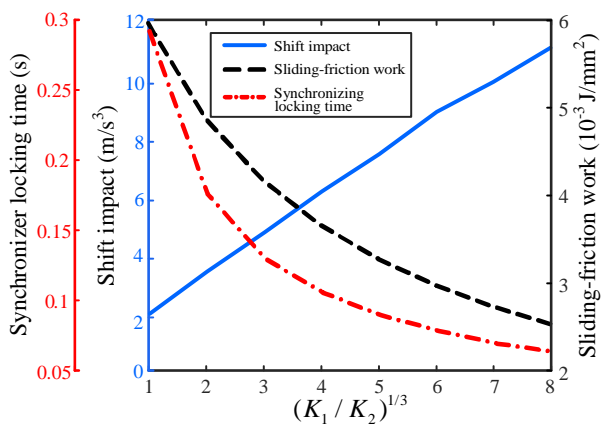

Fig. 10. Relationship between the shift quality and $\left(K_{1} / K_{2}\right)^{1 / 3}$.

As can be found in Fig. 10, with the increase of shift impact, the synchronizer locking time and sliding-friction work are reduced. However, the value of sliding-friction work is much less than the allowed value. Therefore, the shifting quality depends on the synchronizer locking time and shift impact. The optimal performance in this phase can be evaluated according to the limit of shift impact, which should be lower than $10 \mathrm{~m} / \mathrm{s}^{3}$. Therefore, $\left(K_{1} / K_{2}\right)^{1 / 3}$ can be determined, and the optimal torque trajectory of the control motor is finally yielded, as:

$$
T_{s m}= \begin{cases}T_{s m}\left(t_{0}\right) e^{6.8 \cdot\left(\frac{J_{v e} i_{0}}{2 r^{2}}\right)^{1 / 3}\left(t-t_{0}\right)} & 0<T_{s m}<0.4775 \\ 0.4775 & T_{s m} \geq 0.4775\end{cases}
$$

\section{SimUlation AND EXPERIMENT VALIDATION}

To test the effectiveness of the proposed shift mechanism and shifting strategy of 2AT for EV applications, simulation based on Matlab/Simulink and experimental validation of a prototype are conducted. The upshift and downshift processes are performed for evaluation.

\section{A. Simulation Results of the Upshifting process}

We assume that the upshift speed is $50 \mathrm{~km} / \mathrm{h}$ for simulation validation. Fig. 11 shows the camshaft position and the timing of the motor in this process. Fig. 11 (a) shows the camshaft position corresponding to Fig. 7. Fig. 11 (b) depicts the timing of the control motor, in which " 0 " represents a non-working mode, "1" represents the pre-gear-disengagement, "2" represents the gear-disengagement, and " 3 " represents the gearengagement. The control motor does not stop operating during the whole shifting process, thus effectively avoiding frequent start and stop and prolonging its working life. Fig. 11 (c) shows the timing of the driving motor, in which " 0 " represents the free mode, " 1 " represents the torque mode, and " 2 " represents the speed adjusting mode. As shown in Fig. 11 (b) and (c), the total duration of parallel control is $0.33 \mathrm{~s}$, which means that if the traditional serial control strategy is applied, the upshift time will increase by $52.46 \%$.

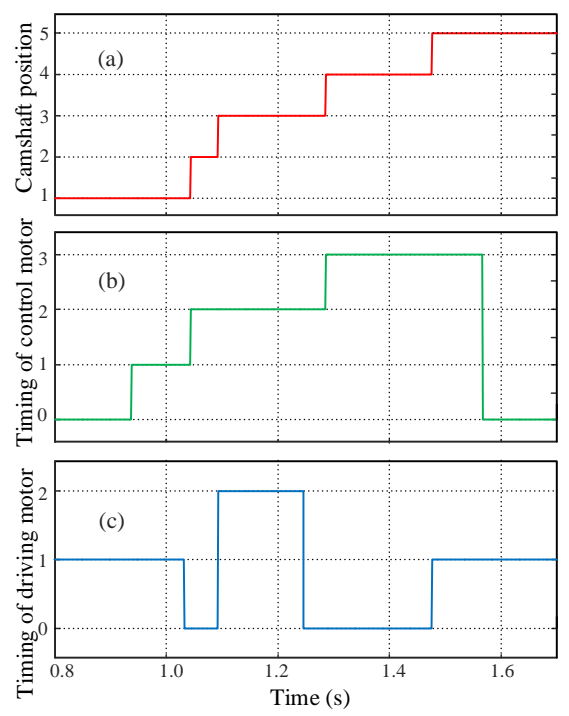

Fig. 11. Camshaft position and motor timing.

Fig. 12 and Table $\mathrm{V}$ detail the simulation results of the synchronizing process. The sleeve speed increases first and then decreases, according to Fig. 12 (a), (c) and (d). Moreover, the maximum sleeve speed is lower than $0.12 \mathrm{~m} / \mathrm{s}$ during the before-synchronizer-locking phase, and the minimum speed is 
$0.032 \mathrm{~m} / \mathrm{s}$. Therefore, the PI controller may not only reduce the gap quickly, but also control the speed well so as to avoid the phenomenon of tooth braking and the associated impact.

TABLE V

SHIFT QUALITY RESULTS OF UPSHIFT IN THE SYNCHRONIZING PROCESS.

\begin{tabular}{lllll}
\hline \hline $\begin{array}{l}\text { Evaluation } \\
\text { index }\end{array}$ & $\begin{array}{l}\text { Synchronizing } \\
\text { time }\end{array}$ & $\begin{array}{l}\text { Time of } \\
\text { synchronizer- } \\
\text { locking phase }\end{array}$ & $\begin{array}{l}\text { Maximum } \\
\text { shift } \\
\text { impact }\end{array}$ & $\begin{array}{l}\text { Sliding- } \\
\text { friction } \\
\text { work }\end{array}$ \\
\hline Value & $0.189 \mathrm{~s}$ & $0.061 \mathrm{~s}$ & $6.19 \mathrm{~m} / \mathrm{s}^{3}$ & $1.25 \mathrm{~J}$ \\
\hline \hline
\end{tabular}

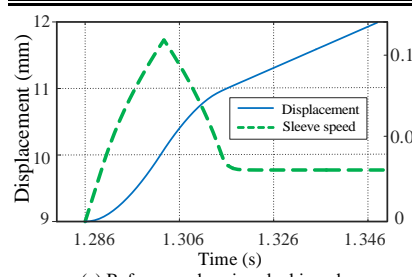

(a) Before-synchronizer-locking phrase

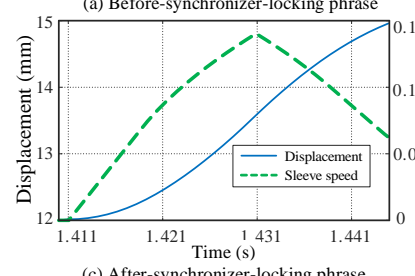

(c) After-synchronizer-locking phrase

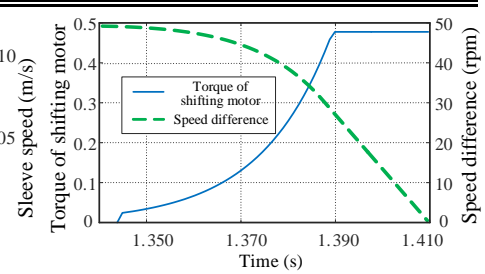

(b) Synchronizer-locking phase

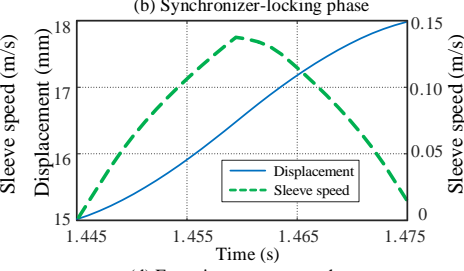

(d) Engaging-target-gear phase
Fig. 12. Simulation results of the synchronizing process. (a) Beforesynchronizer-locking phase; (b) Synchronizer-locking phase; (c) Aftersynchronizer-locking phase; (d) Engaging-target-gear phase.

In the synchronizer-locking phase, the control motor increases torque rapidly to the maximum output torque for eliminating the speed difference between the driving and driven parts, and the total time for this phase is only $0.069 \mathrm{~s}$. Simultaneously, the maximum shift impact is $6.19 \mathrm{~m} / \mathrm{s}^{3}$, which is less than the limit of maximum shift impact. Therefore, the shift quality is obviously improved by the control algorithm for synchronizing torque optimization, in terms of responsiveness and smoothness.

As shown in Fig. 13, the shift impact during shifting process is less than $10 \mathrm{~m} / \mathrm{s}^{3}$, the speed fluctuation is low, and the shifting time is $0.602 \mathrm{~s}$. Besides, the vehicle speed increases and maintains the preferable power performance. It can be found that the novel shift mechanism and proposed shifting control strategy can realize a fast and smooth upshift.
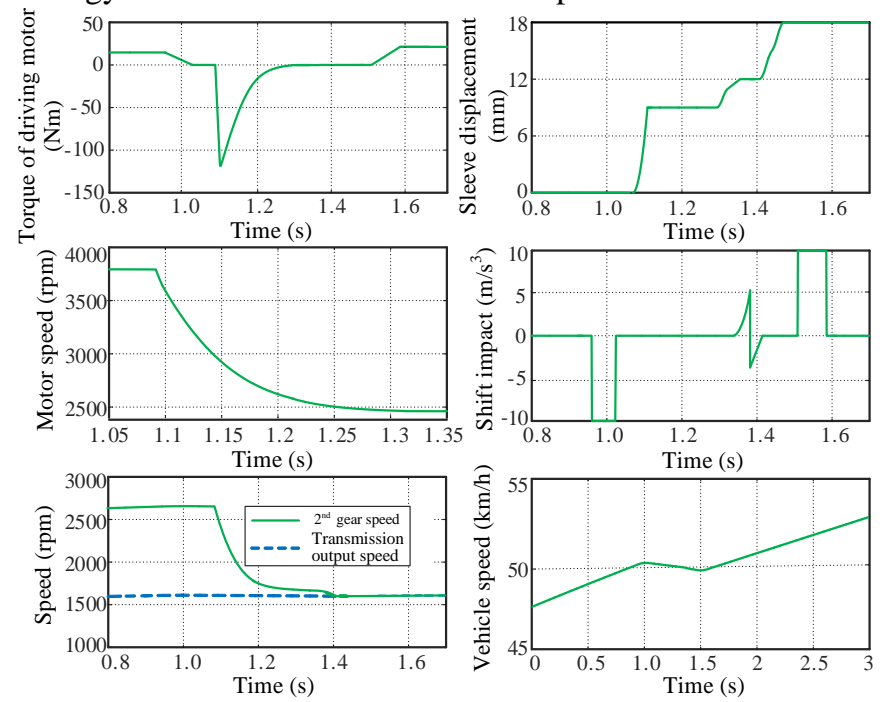

Fig. 13. Simulation results for the upshifting process.

\section{B. Simulation Results of the Downshifting process}

Fig. 14 shows the simulation results of downshifting process. As can be seen, the time of the downshifting process is $0.675 \mathrm{~s}$, slightly longer than the upshifting process, but still less than 1 s. The shift impact during the whole downshifting process is also within the limit. Thus, the proposed control strategy is justified.
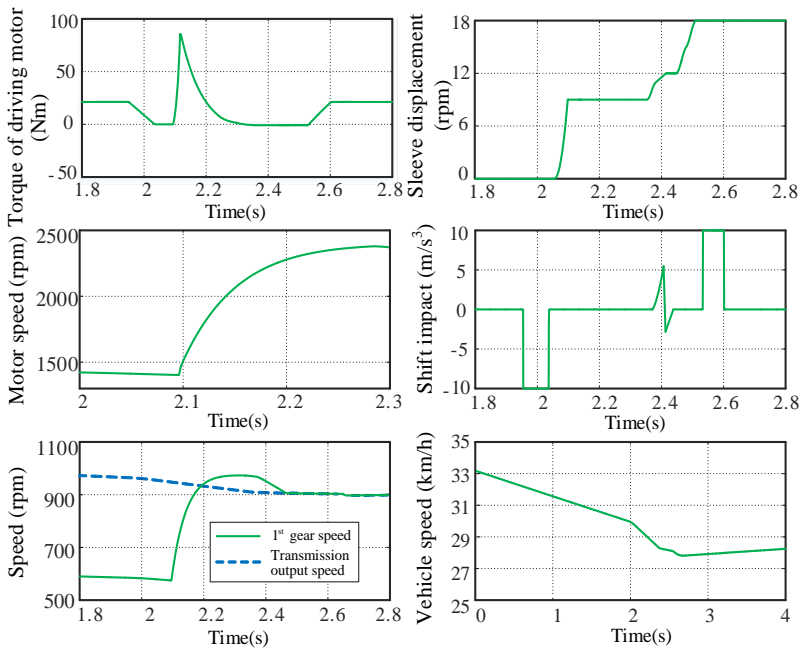

Fig. 14. Simulation results of the downshifting process.

\section{Experiment Results of the Shifting Process}

A prototype including the transmission and shifting mechanism is fabricated in real scale, as shown in Figs. 15 and 16 , to evaluate the proposed design and control method. The test bench is composed of the 2AT system with a transmission control unit (TCU), a driving motor, a motor control unit (MCU), an inertia flywheel and a load motor. The output torque of the transmission is measured by a torque sensor.

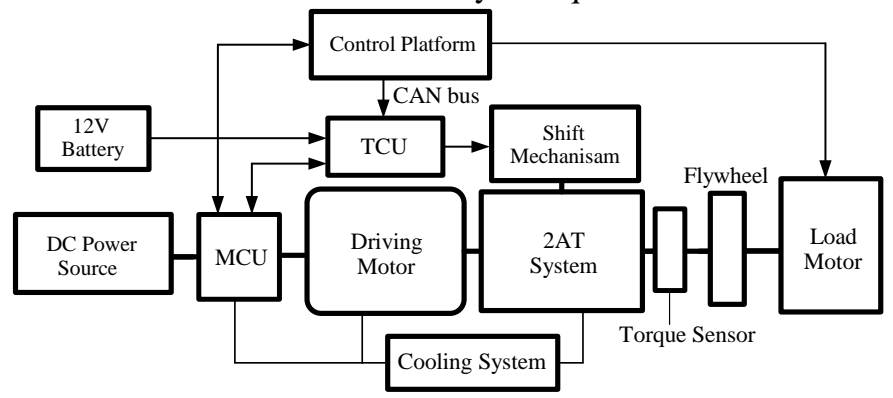

Fig. 15. Configuration of the test bench.

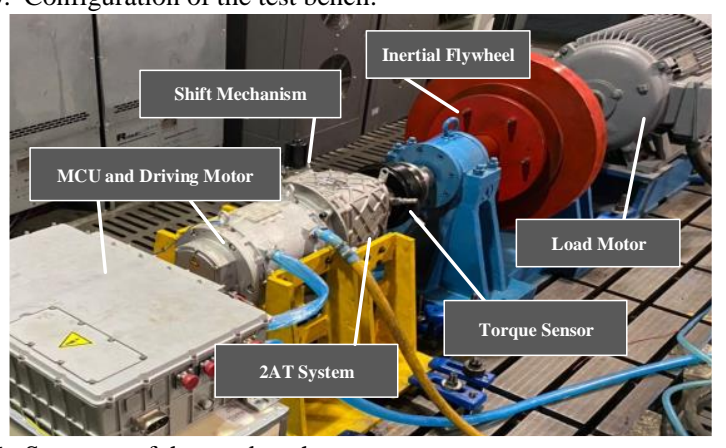

Fig. 16. Structure of the test bench.

The experiment results of upshifting and downshifting processes are as Fig. 17. The time of upshifting and downshifting is $0.60 \mathrm{~s}$ and $0.72 \mathrm{~s}$, respectively. Moreover, the fluctuation of transmission output torque is quite low, 
guaranteeing the comfort during shifting. As can also be found from Fig. 17, the shifting impact in the experimental result showcases a similar trend, compared to the simulation results. That is, regarding the torque-release/restoration process at the beginning and end of the shifting process, the experimental results show that the motor can quickly complete torque adjustment in about $0.1 \mathrm{~s}$ and suppresses the shifting impact under the limit of $10 \mathrm{~m} / \mathrm{s}^{3}$. In the gear-engagement process, which occurs from $0.46 \mathrm{~s}$ to $0.6 \mathrm{~s}$ (see Fig. 17 (a)) and from 0.57 $\mathrm{s}$ to $0.73 \mathrm{~s}$ (as shown in Fig. 17 (b)), the shifting impact caused by the synchronizer locking is controlled within around $5 \mathrm{~m} / \mathrm{s}^{3}$.
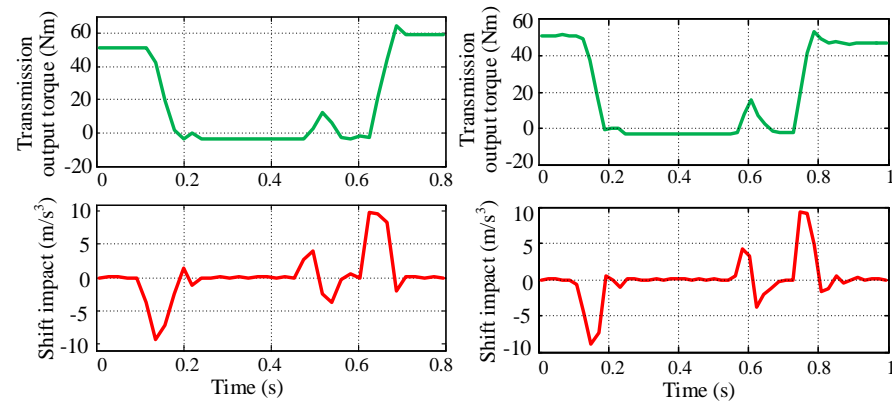

(a)

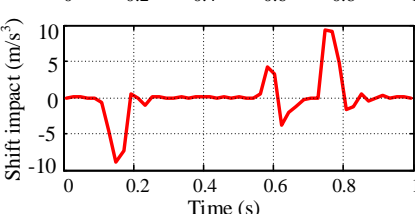

(b)

Fig. 17. The experimental results for the shifting process. (a) Upshifting process; (b) Downshifting process.

Furthermore, the system detailed in [22] is introduced for shifting performance comparison. In this benchmark system, the motor and transmission are also directly connected without clutch, and an active-synchronization strategy is implemented for the speed synchronization of the motor and transmission. Note that the shifting time of the system in [22] is $0.79 \mathrm{~s}$. Instead, as can be found from Fig. 18, the shift time of the proposed system is $9.8 \%$ faster than the benchmark system. Moreover, the maximum shift impact during gear engagement process of the proposed system is $4.6 \mathrm{~m} / \mathrm{s}^{3}$, which is $8 \%$ less than that of the benchmark system. Additionally, the maximum shifting impact during the whole process is almost identical, both within $10 \mathrm{~m} / \mathrm{s}^{3}$. In short, the designed 2AT system associated with the advanced control algorithm outperforms the system in [22]. To sum up, the proposed novel 2AT system for EV achieves the anticipated shifting performance through the validation of the comprehensive test.
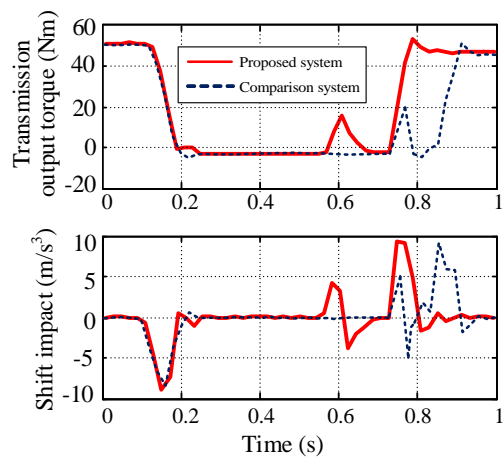

Fig. 18. The comparison results of the shifting process.

\section{CONCLUSION}

In this paper, a $2 \mathrm{AT}$ system is put forward with a special shift mechanism, which is composed of a control motor, a worm gear mechanism and camshaft, and features small size, rapid shifting, and simple structure. A parallel coordination control strategy for the control motor and driving motor is developed for the shifting processes. The control algorithm with an optimization of synchronizing torque based on PMP is proposed to significantly improve the shift quality in terms of shift responsiveness and smoothness. The validation of the shifting processes is conducted, and the effectiveness of the novel 2AT system was verified on test bench.

Although this research has validated the effectiveness of a prototype for the proposed 2AT on best bench, some work still needs to be performed to achieve its application. The parameter design of shift mechanism is based on a flat surface, and theoretically, there is a reasonably curved surface for force application to maximize the acceleration of shifting fork at each position, which can reduce the shift time. Moreover, it is necessary to carry out tests concerning the transmission efficiency, noise, dynamic stiffness, and fatigue life to verify the transmission performance and durability.

\section{REFERENCE}

[1] R. Dua, K. White, and R. Lindland, "Understanding potential for battery electric vehicle adoption using large-scale consumer profile data," Energy Reports, vol. 5, pp. 515-524, 2019/11/01/ 2019.

[2] Y. G. Liu, J. Li, Z. Chen, D. T. Qin, and Y. Zhang, "Research on a multiobjective hierarchical prediction energy management strategy for range extended fuel cell vehicles," Journal of Power Sources, vol. 429, pp. 5566, Jul 2019.

[3] X. S. Hu, C. M. Martinez, and Y. L. Yang, "Charging, power management, and battery degradation mitigation in plug-in hybrid electric vehicles: A unified cost-optimal approach," Mechanical Systems and Signal Processing, vol. 87, pp. 4-16, Mar 2017.

[4] Q. Ren, D. A. Crolla, A. Morris, and Ieee, Effect of Transmission Design on Electric Vehicle (EV) Performance (2009 Ieee Vehicle Power and Propulsion Conference, Vols 1-3). 2009, pp. 1086-1091.

[5] L. L. Guo, B. Z. Gao, Q. F. Liu, J. H. Tang, and H. Chen, "On-line Optimal Control of the Gearshift Command for Multispeed Electric Vehicles," Ieee-Asme Transactions on Mechatronics, vol. 22, no. 4, pp. 1519-1530, Aug 2017.

[6] J. G. Ruan, P. Walker, and N. Zhang, "A comparative study energy consumption and costs of battery electric vehicle transmissions," Applied Energy, vol. 165, pp. 119-134, Mar 2016.

[7] F. Nicola, A. Sorniotti, T. Holdstock, F. Viotto, and S. Bertolotto, "Optimization of a Multiple-Speed Transmission for Downsizing the Motor of a Fully Electric Vehicle," SAE International Journal of Alternative Powertrains, vol. 1, pp. 134-143, 07/30 2012.

[8] Y. B. Bang and M. Yoon, "3-Speed Transmission Using Dual Motors and One-Way Clutches," Ieee-Asme Transactions on Mechatronics, vol. 21, no. 1, pp. 412-418, Feb 2016.

[9] M. J. Zhao, J. H. Shi, C. Lin, and J. Z. Zhang, "Application-Oriented Optimal Shift Schedule Extraction for a Dual-Motor Electric Bus with Automated Manual Transmission," Energies, vol. 11, no. 2, Feb 2018, Art. no. 325 .

[10] B. Zhu, N. Zhang, P. Walker, W. Zhan, X. Zhou, and J. Ruan, "TwoSpeed DCT Electric Powertrain Shifting Control and Rig Testing," Advances in Mechanical Engineering, 2013 2013, Art. no. 323917.

[11] P. Walker, B. Zhu, and N. Zhang, "Powertrain dynamics and control of a two speed dual clutch transmission for electric vehicles," Mechanical Systems and Signal Processing, vol. 85, pp. 1-15, Feb 152017.

[12] B. Stubbs and P. Ceng, "eDCT: 4 speed seamless-shift technology for electric vehicles," 2013.

[13] A. Sorniotti, S. Subramanyan, A. Turner, C. Cavallino, F. Viotto, and S. Bertolotto, "Selection of the Optimal Gearbox Layout for an Electric Vehicle," SAE International Journal of Engines, vol. 4, pp. 1267-1280, $06 / 152011$.

[14] A. S. Abdelrahman, K. S. Algarny, M. Z. Youssef, and Ieee, "Optimal Gear Ratios Selection for a Nissan Leaf: A Case Study of InGear Transmission System," in 2017 Ieee Energy Conversion Congress and Exposition(IEEE Energy Conversion Congress and Exposition, 2017, pp. 2079-2085.

[15] G. Lucente, M. Montanari, and C. Rossi, "Modelling of an automated manual transmission system," Mechatronics, vol. 17, no. 2-3, pp. 73-91, Mar-Apr 2007. 
[16] P. D. Walker, S. A. Rahman, B. Zhu, and N. Zhang, "Modelling, Simulations, and Optimisation of Electric Vehicles for Analysis of Transmission Ratio Selection," Advances in Mechanical Engineering, 2013 2013, Art. no. 340435.

[17] C.-Y. Tseng and C.-H. Yu, "Advanced shifting control of synchronizer mechanisms for clutchless automatic manual transmission in an electric vehicle," Mechanism and Machine Theory, vol. 84, pp. 37-56, Feb 2015.

[18] F. Meng, G. Tao, T. Zhang, Y. H. Hu, and P. Geng, "Optimal shifting control strategy in inertia phase of an automatic transmission for automotive applications," Mechanical Systems and Signal Processing, vol 60-61, pp. 742-752, Aug 2015.

[19] P. D. Walker, Y. H. Fang, and N. Zhang, "Dynamics and Control of Clutchless Automated Manual Transmissions for Electric Vehicles," Journal of Vibration and Acoustics-Transactions of the Asme, vol. 139, no. 6, Dec 2017, Art. no. 061005.

[20] L. Chen et al., "Design and validation of clutch-to-clutch shift actuator using dual-wedge mechanism," Mechatronics, vol. 42, pp. 81-95, Apr 2017.

[21] Z. Q. Sun, B. Z. Gao, J. Q. Jin, and K. Sanada, "Modelling, Analysis and Simulation of a Novel Automated Manual Transmission with Gearshift Assistant Mechanism," International Journal of Automotive Technology, vol. 20, no. 5, pp. 885-895, Oct 2019.

[22] H. Chen, X. Cheng, and G. Tian, "Modeling and Analysis of GearShifting Process of Motor-Transmission Coupled Drive System," Journal of Computational and Nonlinear Dynamics, vol. 11, no. 2, Mar 2016, Art. no. 021013.

[23] M. Roozegar and J. Angeles, "The optimal gear-shifting for a multi-speed transmission system for electric vehicles," Mechanism and Machine Theory, vol. 116, pp. 1-13, Oct 2017.

[24] H. X. Chen, X. X. Cheng, and G. Y. Tian, "Modeling and Analysis of Gear-Shifting Process of Motor-Transmission Coupled Drive System," Journal of Computational and Nonlinear Dynamics, vol. 11, no. 2, Mar 2016, Art. no. 021013.

[25] P. Bera, "A design method of selecting gear ratios in manual transmissions of modern passenger cars," Mechanism and Machine Theory, vol. 132, pp. 133-153, Feb 2019.

[26] S. S. Lin and B. Li, "Shift Force Optimization and Trajectory Tracking Control for a Novel Gearshift System Equipped With Electromagnetic Linear Actuators," Ieee-Asme Transactions on Mechatronics, vol. 24, no. 4, pp. 1640-1650, Aug 2019.

[27] P. Gong, J. Meng, and J. Xi, "Adaptive Control of Synchromesh Shifting Process for Automated Manual Transmission," in Future Material Research and Industry Application, Pts 1 and 2, vol. 455-456, K. S. Thaung, Ed. (Advanced Materials Research, 2012, pp. 1132-1135.

[28] H. Naunheimer, B. Bertsche, J. Ryborz, and W. Novak, "Gearshifting Mechanisms," in Automotive Transmissions: Fundamentals, Selection, Design and ApplicationBerlin, Heidelberg: Springer Berlin Heidelberg, 2011, pp. 300-370.

[29] S. Onori, L. Serrao, and G. Rizzoni, "Pontryagin's Minimum Principle," in Hybrid Electric Vehicles: Energy Management StrategiesLondon: Springer London, 2016, pp. 51-63.

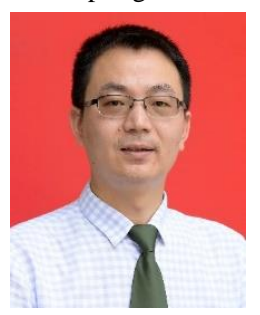

Yonggang Liu, IEEE Senior Member, received the B.S and Ph.D. degrees in automotive engineering from Chongqing University, Chongqing, China, in 2004 and 2010, while he was a joint PhD of University of Michigan-Dearborn, MI, USA, from 2007 to 2009.

Now he is a Professor with the College of Mechanical and Vehicle Engineering, Chongqing University. His research interests mainly include optimization and control of intelligent electric vehicles power system, and integrated control of automatic transmissions. He has leaded more than 20 research projects, such as National Natural Science Foundation of China and Ph.D. Programs Foundation of Ministry of Education of China. More than 70 research papers have been published and 10 patents have been awarded.

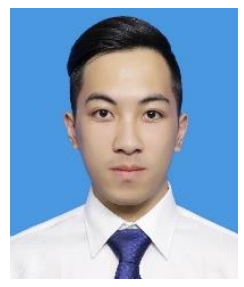

Jun Xie received the B.S. in mechanical engineering from South China Agricultural University, Guangzhou, China, in 2018. He is now pursuing the M.S. in mechanical engineering at Chongqing University, Chongqing, China.

His research is mainly focused on optimal control and automatic transmission for electric vehicles.

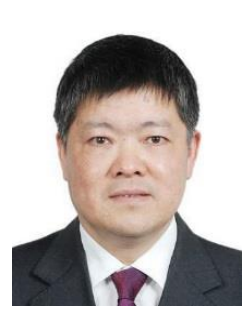

Datong Qin received the B.S., M.S. and Ph.D. in mechanical engineering from Chongqing University, Chongqing, China, in 1982, 1984, and 1993, respectively. In 1989, he was a joint $\mathrm{PhD}$ of Tohoku University, Sendai, Miyagi, Japan.

$\mathrm{He}$ is currently a Professor of College of Mechanical and Vehicle Engineering at Chongqing University, Chongqing, China. His research interests include control and application of mechanical transmission and vehicle power transmission. He has conducted more than 60 projects and has published more than 200 peerreviewed journal papers and conference proceedings. He is the receiver of Changjiang Scholar Program of China and two first prizes of provincial-level scientific and technological progress awards in 2008 and 2010.

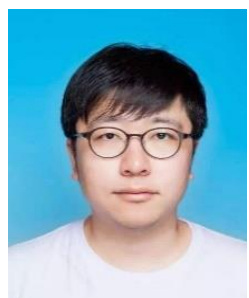

Yuanjian Zhang received the M.S. in Automotive Engineering from the Coventry University, UK, in 2013, and the Ph.D. in Automotive Engineering from Jilin University, China, in 2018. In 2018, he joined the University of Surrey, Guildford, UK, as a Research Fellow in advanced vehicle control.

From 2019, he starts to work in Sir William Wright Technology Centre, Queen's University Belfast, UK. His current research interests include advanced control on electric vehicle powertrains, vehicle-environmentdriver cooperative control, vehicle dynamic control, and intelligent control for driving assist system.

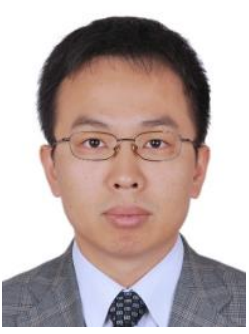

Zheng Chen received the B.S. and M.S. degrees in electrical engineering and the Ph.D. degree in control science engineering from Northwestern Polytechnical University, Xi'an, China, in 2004, 2007, and 2012, respectively. He was a Post-Doctoral Fellow and a Research Scholar with the University of Michigan, Dearborn, MI, USA, from 2008 to 2014.

$\mathrm{He}$ is currently a Professor with the Faculty of Transportation Engineering, Kunming University of Science and Technology, Kunming, Yunnan, China, and a Marie-Curie Research Fellow with the School of Engineering and Materials Science, Queen Mary University of London, London, UK. He has conducted over 30 projects and has published over 130 peerreviewed journal papers and conference proceedings. His research interests include battery management and control of intelligent electric vehicles.

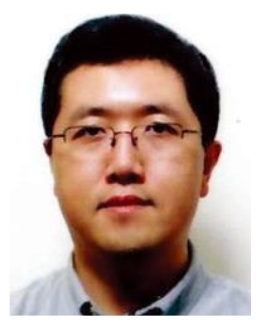

Guang $\mathbf{L i}$ received the Ph.D. degree in electrical and electronics engineering, specialized in control systems, from the University of Manchester, Manchester, U.K., in 2007.

He is currently a Reader in Dynamics Modeling and Control with the Queen Mary University of London, London, U.K. His research interests include constrained optimal control, model predictive control, adaptive robust control and control applications including renewable energies, energy storage, etc.

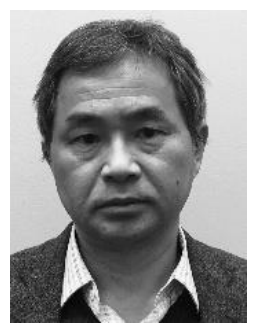

Yi Zhang received the B.S. degree in mechanical engineering from Central South University, Changsha, China, in 1982. He received his M.S., and Ph.D. degrees in mechanical engineering from University of Illinois, Chicago, USA, in 1985 and 1989, respectively. He is a professor at Department of Mechanical Engineering in University of Michigan-Dearborn, USA.

His areas of interest include design and analysis of gearing systems, theory of gearing and applications, vehicle powertrains, and design and analysis of power transmission systems. He has published dozens academic papers in these areas. 